\title{
Práticas laborais de indígenas Galibi-Marworno e modos de medir: pesquisa em etnomatemática
}

\author{
Galibi-Marworno indigenous labor practices and modes of measure: \\ research in ethnomathematics
}

\section{Alarcidio Figueiredo Narciso ${ }^{1}$ Eliane Leal Vasquez ${ }^{2}$}

\begin{abstract}
RESUMO: Este artigo registra os modos de medir que identificamos em algumas práticas laborais de indígenas Galibi-Marworno. Inicialmente, realizamos um levantamento de pesquisa em etnomatemática. Outros dados foram coletados como parte da pesquisa qualitativa, com aplicação de roteiro de entrevista temática a seis Galibi-Marworno. As entrevistas ocorreram na aldeia Kumarumã, no sítio chamado de Casa Velha e às margens do Igarapé Paramuaká, na Terra Indígena Uaça, localizada ao norte do Brasil. Os indígenas Galibi-Marworno usam um sistema de medida diferenciado que envolve medidas de comprimento, de largura, de espessura e de áreas de terrenos. As unidades de medidas documentadas neste estudo foram (braça normal de um homem, metro antigo, dedo, chave, palmo, polegada e braça marítima). Com base na análise das entrevistas, constatou-se que não existe convenção matemática entre essas unidades de medidas para o grupo pesquisado, o que se justifica porque cada coisa ou objeto pode assumir tamanhos diversos no processo de medição. As medições dependem do tipo de recurso natural e da parte do corpo humano que é usado no ato de medir. No Brasil, o Sistema Internacional de Unidades (SI) faz parte do currículo escolar e ele é ensinado à população urbana e rural nas escolas públicas, bem como aos povos indígenas. Mesmo assim, os indígenas Galibi-Marworno não usam as unidades de medidas do SI, em atividades da agricultura ou construções de canoas, casas, peças de madeiras e jamaxis.

Palavra-chave: Ensino de Ciências, Etnomatemática, Cultura Galibi-Marworno, Práticas laborais, Sistema de Medida Diferenciado.
\end{abstract}

ABSTRACT: This paper registers the modes of measuring that we identify in some labor practices of Galibi-Marworno natives. Initially, we carried a survey on research in ethnomathematics. Then, other data collected as part of the qualitative research, with the application of a thematic interview script to six Galibi-Marworno. The interviews took at Kumarumã village, at site called "Casa Velha" and on banks of the "Igarapé Paramuaká," at Uaça Indigenous Land, located to the north of Brazil. The Galibi-Marworno natives use a differentiated measure system that involves measures of length, width, thickness, and areas of land. The units of measure documented in this study were (normal fathom of a man, old meter, finger, key, span, inch, and maritime fathom). Based on the analysis of the interviews, it was found that there is no mathematical convention between these units of measure for the group searched, which justified because each thing or object can assume various sizes in the measurement process. Measurements depend on the type of natural resource and the part of the human body that used in the act of measuring. In Brazil, the International System of Units (SI) make part of the school curriculum, and it is taught to the urban and rural population at public schools, as well as to indigenous people. Even so, the

\footnotetext{
${ }^{1}$ Graduado em Licenciatura Intercultural Indígena pela Universidade Federal do Amapá, com habilitação em Ciências Exatas e da Natureza, professor efetivo do Governo do Estado do Amapá, Escola Indígena Estadual Camilo Narciso e pesquisador do Grupo de Pesquisa História da Ciência e Ensino, E-mail: alarcidionarciso@hotmail.com

${ }^{2}$ Doutora em História da Ciência pela Pontifícia Universidade Católica de São Paulo, Professora Adjunta da Universidade Federal do Amapá, Departamento de Ciências Exatas e Tecnológicas, lotada no Curso de Licenciatura em Matemática e líder do Núcleo de Pesquisa História de Ciência e Ensino, E-mail: elianevasquez@unifap.br
} 
Galibi-Marworno natives do not use the units of measure of this system, in agricultural activities or constructions of canoes, houses, pieces of wood and jamaxis.

Keywords: Teaching of Sciences, Ethnomathematics, Galibi-Marworno Culture, Labor Practices, Differentiated Measure System.

\section{INTRODUÇÃO}

Este artigo foi elaborado, vinculado a linha de pesquisa: Ensino de Ciências, Qualidade de Vida e Cultura Indígena do Núcleo de Pesquisa História da Ciência e Ensino (NUPHCE/UNIFAP/CNPq), que tem como meta "desenvolver projetos de pesquisa e extensão, visando instigar a publicação de obras resultantes de estudos de graduação sobre as temáticas debatidas no Curso de Licenciatura Intercultural Indígena da Universidade Federal do Amapá". (UNIFAP, 2015).

O estudo aborda o resultado do Projeto Pesquisa: Sistema de Medida Diferenciado utilizado em Práticas Laborais pelo Povo Galibi-Marworno: Uma pesquisa em etnomatemática, desenvolvido por Alarcidio Figueiredo Narciso e que participou do Projeto de Extensão - Coleção Monografia: Divulgando a produção discente, registrado sob o $\mathrm{n}^{\circ}$ 091/2014 pelo Departamento de Extensão da Universidade Federal do Amapá (DEX/UNIFAP), coordenado de 2014 a 2016, pela professora Eliane Leal Vasquez e que também orientou o projeto de pesquisa. Também foi selecionado no resultado final do Edital $n^{\circ}$ 008/2015/DEX/PROEAC/UNIFAP, que trata da primeira fase do Projeto de Extensão - Coleção Monografia: Divulgando a produção discente, na área de Ciências Exatas e da Natureza, para publicação em mídia impressa ou digital.

Este trabalho tem como objetivo registrar os modos de medir dos indígenas Galibi-Marworno, em atividades da agricultura, que envolvem a preparação e plantio das roças e também nas medições de recursos naturais para construir canoas, casas e outros objetos, tendo as discussões sobre pesquisa em etnomatemática como suporte teórico.

Partindo de informações coletadas inicialmente sobre o objeto de estudo durante a execução dos temas contextuais do Curso de Licenciatura Intercultural Indígena da UNIFAP, em especial, na área de habitação em Ciências Exatas e da Natureza, os autores formularam como problema de pesquisa: De que modo, os indígenas GalibiMarworno realizam as medições em atividades da agricultura ou para construir canoas ou outros objetos que eles necessitam?

Ao estudar os Parâmetros Curriculares Nacionais do Ensino Médio - PCNEM (BRASIL, 2000), percebe-se que a etnomatemática não é comentada como conceito ou teoria que pode orientar o planejamento de estratégias de ensino. Mas é proposta como parte das estratégias de ensino para a matemática, assim como o uso de projetos de trabalho coletivo, tecnologia na aprendizagem escolar, resolução de problemas, história das ciências e das matemáticas.

A palavra "etnomatemática" foi proposta, em 1977, pelo matemático Ubiratan D'Ambrosio e foi elaborada a partir de três outros termos. Para D'Ambrosio, ETNO signi- 
fica o ambiente natural, social, cultural e imaginário; MATEMA significa explicar, aprender, conhecer e lidar; e, TICA significa os modos, os estilos, as artes e as técnicas dos grupos culturais (ROSA; OREY, 2005; D'AMBROSIO, 2005).

Para D’Ambrosio (2005), a etnomatemática é presente na diversidade de cada grupo cultural. Ele explica que a etnomatemática é hoje considerada uma subárea da História da Matemática e da Educação Matemática, onde esta área de pesquisa tem relação com a Antropologia e as Ciências da Cognição.

Tentar explicar a visão do autor sobre o conceito de etnomatemática não é fácil, pois ele apresenta mais de um conceito quando se refere à etnomatemática.

Mencionamos dois desses conceitos:

Sintetizando, a etnomatemática é um programa que visa explicar os processos de geração, organização e transmissão de conhecimentos em diversos sistemas culturais e as forças interativas que agem nos e entre os três processos [...] (D’AMBROSIO, 1998, p. 7).

Etnomatemática é a matemática praticada por grupos culturais como comunidades urbanas e rurais, grupos de trabalhadores, classes profissionais, crianças de uma de uma faixa etária, sociedades indígenas, e tanto outros grupos que se identificam por objetivos e tradições comuns aos grupos (D'AMBROSIO, 2005, p. 9).

Nestas citações, nota-se que o conceito de etnomatemática é usado de duas formas diferentes. Na primeira, o autor usa a palavra etnomatemática apresentando-a como um programa de pesquisa que se volta para os processos de geração, organização e transmissão de conhecimentos que se manifestam em diferentes ambientes e culturas. Já na segunda, o autor emprega o termo "etnomatemática" para referir-se a matemática praticada por diferentes grupos culturais, isto é, distintos grupos de pessoas que convivem entre si, complementado a primeira definição.

O organograma a seguir, resume o que D’Ambrosio $(1998 ; 2005)$ designou pelo termo "etnomatemática":

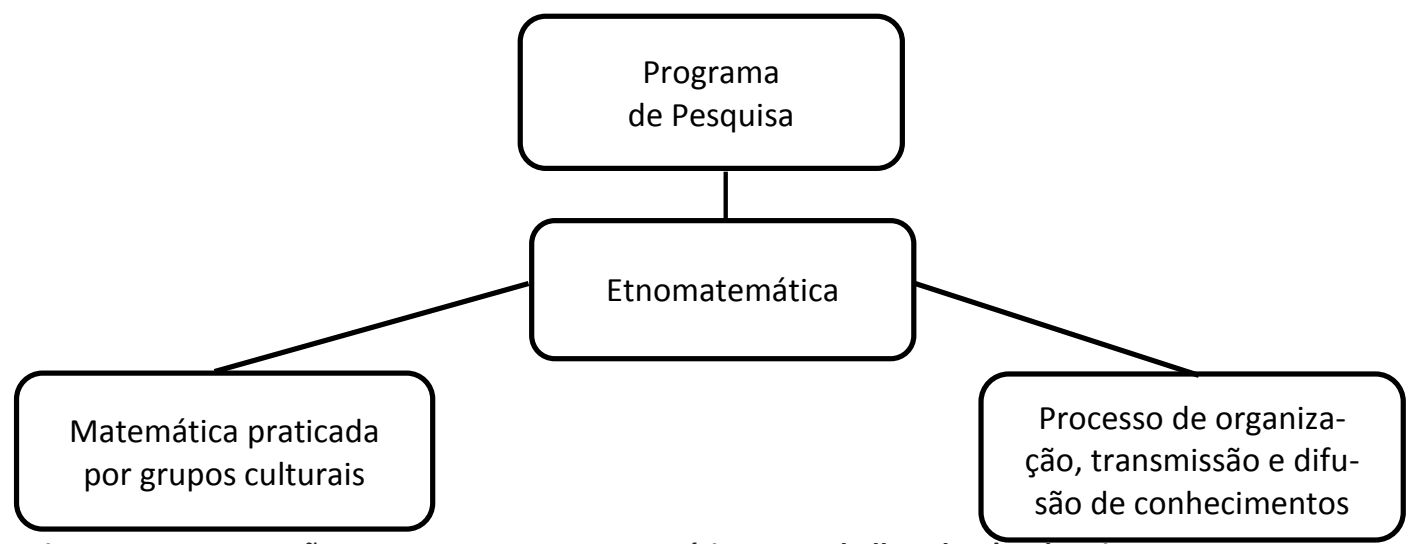

Figura 1 - Interpretações para o termo etnomatemática em trabalhos de D’Ambrosio.

Fonte: Organograma preparado pelos autores. 
As pesquisas em etnomatemática estudam os modos, os estilos, as artes e as técnicas de explicar, aprender, conhecer e lidar em ambiente natural, social, cultural e imaginário de grupos culturais. Assim, a pesquisa em etnomatemática dedica-se à produção dos conhecimentos em geral ou os conhecimentos matemáticos que são de uma cultura. (D’AMBROSIO, 1998; 2005).

O referencial teórico da etnomatemática não é mencionado no PCNEM (BRASIL, 2000), mas como citada como uma das teorias para orientar a elaboração de planos de aulas de matemática. Mesmo assim, entendemos que este conceito e os resultados de estudos desta área de pesquisa auxiliam aos professores a pensar, discutir e propor estratégias de ensino voltadas à educação escolar indígena.

No Curso de Educação Escolar Indígena ${ }^{3}$ e de Licenciatura Intercultural Indígena da UNIFAP, alguns estudantes desenvolveram pesquisa em etnomatemática. Um exemplo é a monografia de Santos (2011), que investigou os significados de treze marcas indígenas da cultura Galibi-Marworno, como as marcas Kuahi, Thas Djiab, Pataje Kasab, Bhãx Uasei, Thas Fomi Mãiok, Uei Sarakurá, Kai Atxipa, Dã Djilo, Kai Txuhi, Iarari, Papiõ, Zétuel Warukamã e Ximê dji lavi a partir da visão dos artesãos Galibi-Marworno e do pajé.

Este foi o primeiro projeto de pesquisa deste curso de graduação, realizado na área de habilitação em Ciências Exatas e da Natureza. Neste também se documentou como os professores não indígenas ${ }^{5}$ têm usado as marcas indígenas em turmas de $5^{-a}$ e $6^{a}$ séries nas aulas de matemática. O resultado da pesquisa mostrou que os professores indígenas mesmo não conhecendo os significados das marcas Galibi-Marworno, já utilizavam as marcas indígenas no ensino de matemática. (SANTOS, 2011).

Exemplificamos, a seguir, outras pesquisas em etnomatemática:

\begin{tabular}{c|l|l}
\hline Autor/Ano & \multicolumn{1}{|c|}{ Pesquisa } & \multicolumn{1}{c}{ Foco } \\
\hline Melo (2007) & $\begin{array}{l}\text { Investigação etnomatemática em contex- } \\
\text { tos indígenas: caminhos para a reorienta- } \\
\text { ção da prática pedagógica }\end{array}$ & $\begin{array}{l}\text { Cultura Xerente, diálogos e reflexões } \\
\text { para reorientação da prática pedagó- } \\
\text { gica }\end{array}$ \\
\hline Cardoso (2007) & $\begin{array}{l}\text { O Céu dos Tukanos na Escola Yupuri: } \\
\text { Construindo um calendário astronômico }\end{array}$ & $\begin{array}{l}\text { Cultura Tukano e construção de um } \\
\text { calendário astronômico para a Escola } \\
\text { Yupuri }\end{array}$ \\
\hline Costa (2008) & $\begin{array}{l}\text { Os tecidos de Gana como atividade esco- } \\
\text { lar: uma intervenção etnomatemática } \\
\text { para a sala de aula }\end{array}$ & $\begin{array}{l}\text { Os tecidos de Gana como manifesta- } \\
\text { ção da cultura africana e proposta de } \\
\text { atividade escolar para o ensino de } \\
\text { matemática }\end{array}$ \\
\hline Vasquez (2008) & $\begin{array}{l}\text { Sociedade Cativa. Entre cultura escolar e } \\
\text { cultura prisional: Uma incursão pela ciên- }\end{array}$ & $\begin{array}{l}\text { Cultura Escolar e Cultura Prisional no } \\
\text { sistema penitenciário amapaense }\end{array}$ \\
\hline
\end{tabular}

\footnotetext{
3 Para mais informações, vide: UNIVERSIDADE FEDERAL DO AMAPÁ. Projeto Político Pedagógico do Curso Educação Escolar Indígena, 2005.

${ }^{4}$ Para saber o que representam estas marcas indígenas, vide: SANTOS, N. Marcas Indígenas do Povo Galibi-Marworno: O despertar do ensino da matemática na escola indígena, 2011.

${ }^{5}$ Estes na época da pesquisa, estavam lotados na Escola Indígena Estadual Camilo Narciso (EIECN/SEED/GEA), localizada na aldeia Kumarumã.
} 


\begin{tabular}{l|l|l}
\hline & cia penitenciária & \\
\hline \multirow{3}{*}{ Londonõ (2011) } & $\begin{array}{l}\text { “La medida” e nun contexto de escuela } \\
\text { indígena: el caso del Pueblo Tule y el caso } \\
\text { del Pueblo Embera-Chamí }\end{array}$ & $\begin{array}{l}\text { As medidas e instrumentos em uso na } \\
\text { Cultura Tule e Cultura Embera-Chamí }\end{array}$ \\
\hline \multirow{2}{*}{ Santos (2011) } & $\begin{array}{l}\text { Marcas Indígenas do Povo Galibi- } \\
\text { Marworno: O despertar do ensino da da } \\
\text { matemática na escola indígena }\end{array}$ & $\begin{array}{l}\text { As marcas da cultura Galibi-Marworno } \\
\text { e reflexões para o ensino de matemá- } \\
\text { tica na escola indígena }\end{array}$ \\
\hline
\end{tabular}

Tabela 1 - Diversidade de objetos de estudo na pesquisa em etnomatemática.

Fonte: Elaborado pelos autores, com base nos resultados das pesquisas de Melo (2007), Cardoso (2007), Costa (2008), Vasquez (2008), Londonõ (2011) e Santos (2011).

Na Tabela 1, destacou-se alguns exemplos de pesquisa em etnomatemática que enfatizaram a riqueza da diversidade cultural de diferentes sociedades, como do Brasil, da Colômbia e da África. Pode-se observar que os seus resultados sistematizaram sobre os conhecimentos e as práticas de grupos culturais, além de evidenciar as suas formas de explicar, conhecer e lidar com ambientes específicos, isto é, que se relacionam com as escolas indígenas, as escolas instaladas dentro das prisões e outras escolas públicas.

Nota-se, inclusive, nessas produções, as questões étnico-raciais, que envolvem as culturas que são transmitidas e ensinadas por distintos povos nos sistemas educacionais. Estas pesquisas foram desenvolvidas nos Programas de Pós-Graduação em Educação (UFRN) e em Educação Matemática (PUC-SP), Programa de Estudos Pós-Graduados em História da Ciência (PUC-SP), como ainda nos cursos de Licenciatura em Educação Básica, com Ênfase em Matemáticas (UDEA) e de Licenciatura Intercultural Indígena (UNIFAP).

\section{METODOLOGIA}

Primeiramente, realizamos um levantamento de estudos sobre etnomatemática e sobre medidas de comprimento com foco em culturas indígenas. A pesquisa bibliográfica realizou-se de forma física e virtual, na Biblioteca Central da Universidade Federal do Amapá (Macapá), Biblioteca do Museu dos Povos Indígena do Norte do Amapá e Pará - Kuahí (Oiapoque), Rede Latinoamericana de Etnomatemática (RELAET), Biblioteca Digital Sapientia da Pontifícia Universidade Católica de São Paulo (PUC-SP) e Biblioteca Digital da Universidade Federal do Rio Grande do Norte (UFRN).

Em seguida, partimos para a pesquisa qualitativa. Segundo D’Ambrosio (2003) esse tipo de pesquisa é caracterizada pela inserção e interação de pessoas em um ambiente sociocultural e natural. Neste estudo, o ambiente sociocultural e natural é a Aldeia do Kumarumã ${ }^{6}$, na Terra Indígena Uaça, localizada ao norte do Brasil. As entrevistas ocorreram no sítio chamado de Casa Velha, onde se faz o plantio da roça e no Igarapé Paramuaká, local onde são construídas as canoas e feitas as medições de terrenos para preparação da roça.

\footnotetext{
${ }^{6}$ Aldeia que se localiza à margem esquerda do médio rio Uaça.
} 
Os procedimentos para definir as pessoas e os locais da pesquisa foram:

- Visita a casa de seis indígenas mais velhos da Aldeia Kumarumã, com objetivo de convidá-los a participar como entrevistados da pesquisa;

- Realização de entrevistas individuais, com seis indígenas mais velhos, no período de março até julho de 2013. Nesta etapa da pesquisa qualitativa, participaram oito pessoas, sendo o acadêmico e pesquisador (Alarcidio Figueiredo Narciso), a assistente de pesquisa (Célia dos Santos Charles) ${ }^{7}$ e os entrevistados (Humberto Monteiro, Lucio Maurício, Orivaldo dos Santos Nunes, Adailson dos Santos Narciso, Firmino dos Santos e Augusto Cesar Narciso Charles).

- Aplicação de roteiro de entrevistas com dois tópicos: 1. Auto apresentação; 2. Medida de comprimento em uso pelos indígenas Galibi-Marworno. Esta etapa foi filmada pela assistente de pesquisa, Célia dos Santos Charles, com finalidade de auxiliar o processo de transcrição dos depoimentos orais, sendo autorizada pelos participantes colaboradores da pesquisa.

- Por último, realizamos a transcrição e a textualização dos depoimentos orais, finalizando com a assinatura da carta de autorização de uso de depoimento oral e imagem, sob a responsabilidade do acadêmico e pesquisador (Alarcidio Figueiredo Narciso); e, análise do conteúdo, com apoio da orientadora do projeto de pesquisa (Eliane Leal Vasquez), etapa realizada na Universidade Federal do Amapá/Campus Binacional de Oiapoque, no ano de 2014.

A Figura 2 mostra o acadêmico-pesquisador, quase ao centro, com um entrevistado (à sua esquerda), uma assistente de pesquisa (à sua direita) e mais cinco entrevistados (demais pessoas):

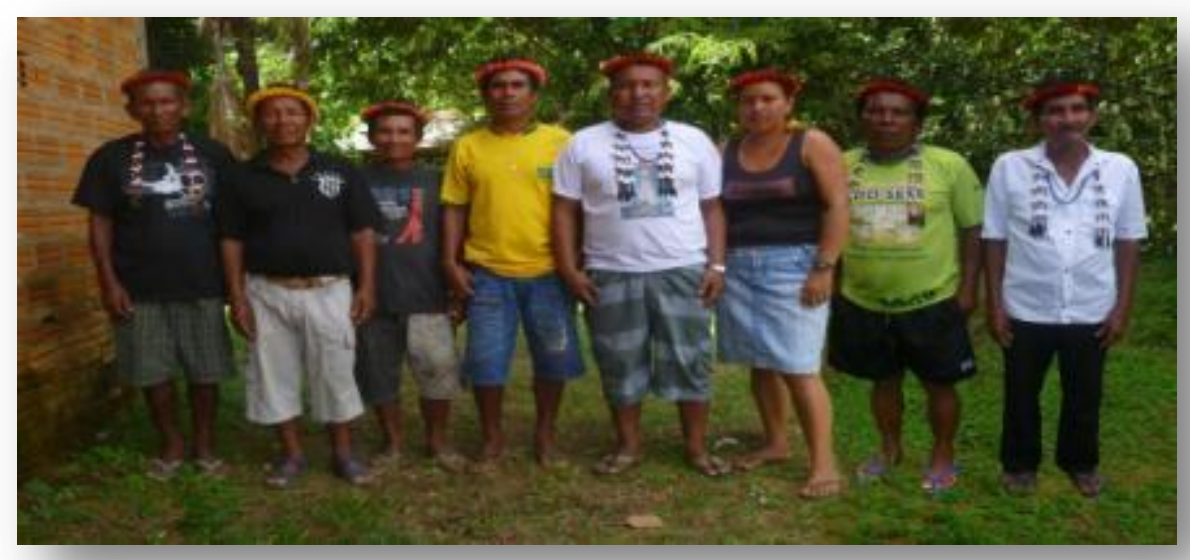

Figura 2 - Registro fotográfico da pesquisa qualitativa.

Fonte: Narciso, A. F. Fotografia da pesquisa, 2013a.

O critério para seleção dos entrevistados foi a quantidade de seis indígenas Ga-

\footnotetext{
${ }^{7}$ Graduada em Licenciatura Intercultural Indígena (UNIFAP), com habilitação em Linguagem e Códigos e professora efetiva da Escola Indígena Estadual Camilo Narciso (EIECN/SEED/GEA).
} 
libi-Marworno mais velhos, com faixa etária entre quarenta e sete a sessenta e cinco anos. $\mathrm{O}$ total de entrevistados se definiu à medida que o acadêmico-pesquisador entrou em contato com os moradores da Aldeia Kumarumã e eles manifestaram oralmente interesse em participar da pesquisa como entrevistados.

Esta quantidade foi suficiente por se tratar de uma pesquisa qualitativa. Neste caso, o mais importante são os saberes dos indígenas Galibi-Marworno e não a quantidade de pessoas que detém os conhecimentos sobre o sistema de medida diferenciado ou modos de medir.

\section{RESULTADO E DISCUSSÃO}

A seguir, apresentaremos a análise das entrevistas, estabelecendo um diálogo entre as respostas transcritas dos depoimentos orais e as perguntas feitas pelo entrevistador.

Destacamos que as entrevistas foram realizadas em português entre os falantes que tinham maior domínio nesta língua; no segundo grupo, em língua Kheuol, as perguntas e respostas; e no último grupo, as perguntas foram feitas em português e língua Kheuol, momento em que as respostas foram em língua Kheuol. Adotamos o uso de duas línguas durante a realização das entrevistas individuais para explicar ao grupo de entrevistados, o roteiro de entrevista e o objetivo da pesquisa.

As entrevistas iniciaram com a seguinte pergunta: Qual o seu nome (ou apelido), etnia, idade, atividade ou trabalho desenvolvido na Aldeia Kumarumã no cotidiano?

Meu nome é Humberto Monteiro e meu apelido é Xinuã (Chinês), tenho cinquenta e um anos e sou da Etnia Galibi-Marworno. Na aldeia Kumarumã, eu trabalho na roça, faço canoa, faço Peneira fina para passar açaí e caxixi, peneira para passar farinha e tapioca, paneiro, flecha, plumaria, maracá, miçanga, pulseira, anel, colher de madeira, remo e outros (MONTEIRO, 2013).

Meu nome é Lucio Mauricio e meu apelido é Lus (Lucio), tenho sessenta anos e sou da Etnia Galibi-Marworno. Na aldeia Kumarumã, eu trabalho na roça, pesca e as vezes na caça. Também faço canoas, remos, peneiras, tipitis, abanos, paneiro, flechas e $\operatorname{arcos}$ (MAURICIO, 2013).

Meu nome é Orivaldo dos Santos Nunes e meu apelido é Tag, tenho cinquenta e três anos e sou da Etnia Galibi-Marworno. Eu trabalho na roça, na pesca e com construção de canoas e produção de farinha (NUNES, 2013).

Meu nome é Adailson dos Santos Narciso e meu apelido é Soda (Soldado). Tenho quarenta e sete anos e sou da Etnia Galibi-Marworno. Trabalho na roça, na pesca, produção de farinha, serragem de madeira da floresta para construir as canoas e os remos (NARCISO, 2013).

Meu nome é Firmino dos Santos (Txifé) e meu apelido é Mãguai (passarinho - kuei- 
kuei), tenho sessenta e cinco anos e sou da Etnia Galibi-Marworno. Trabalho na roça, na pesca, com limpeza de suas plantações perto de casa. Também trabalho fazendo jamaxi (cesto de carregar mandioca) e na produção da farinha (SANTOS, 2013).

Meu nome é Augusto Cesar Narciso Charles e meu apelido é Txigus. Tenho cinquenta e três anos e sou da Etnia Galibi-Marworno. Trabalho na roça e na pesca, e, com produção de farinha, construção de canoas, remos e jamaxi (CHARLES, 2013).

Portanto, os entrevistados da pesquisa são indígenas pertencentes a etnia Galibi-Marworno e são agricultores que trabalham na Aldeia Kumarumã e nas suas proximidades. Em seguida, partimos para o segundo eixo-temático das entrevistas individuais, com a seguinte pergunta: Como os moradores da Aldeia Kumarumã mediam as coisas no passado antes dos indígenas Galibi-Marworno terem acesso a trena, régua, esquadro e outros instrumentos de medidas?

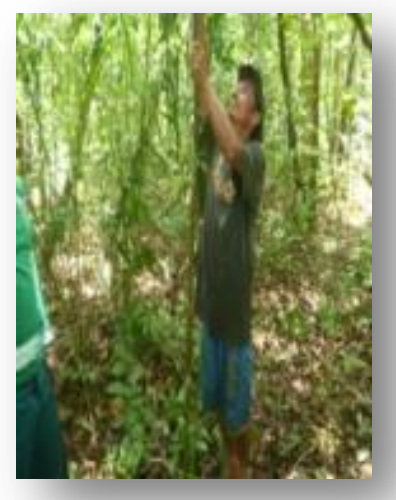

Fonte: Narciso, A. F. Fotografia da pesquisa, 2013b.

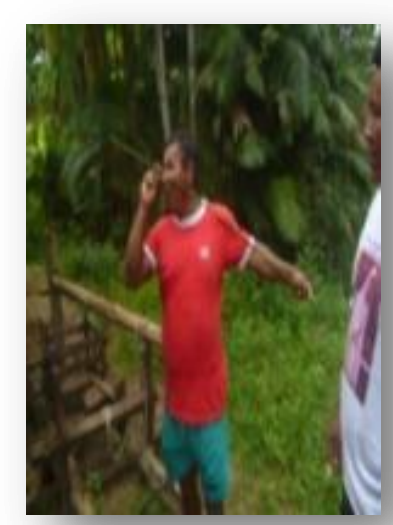

Fonte: Narciso, A. F. Fotografia da pesquisa, $2013 \mathrm{~b}$.
Os indígenas Galibi-Marworno no passado mediam as coisas usando a braça marítima (tuéz). A braça marítima é um homem em pé, com o braço esticado para cima e segurando um terçado. Esta medida vai da ponta do dedo do pé do homem até a ponta do terçado, medindo numa vara para cima. No passado e hoje, a braça marítima é usada para medir o comprimento e largura das roças. Também usavam a braça normal. A braça normal é um homem em pé de braços abertos. Esta serve para medir canoa casco, por exemplo, uma canoa pode medir duas braças e meia de comprimento ou três braças até quatro braças de comprimento. No passado, também era usado o metro antigo. 0 metro antigo é igual a cinco palmos. Numa mão aberta se mede o palmo, que vai da ponta do dedo polegar até o dedo mínimo. A medida dos cinco palmos se mede com uma vara, esse comprimento, e então, se tem o metro antigo ou metro indígena. Era assim que os indígenas no passado mediam as coisas, antes de ter contato com o metro não indígena. (MONTEIRO, 2013).

No passado e também hoje é usado o metro antigo. Este é o braço de um homem erguido numa vara pequena, segurando uma vara na mão, com a cabeça virada para direita, mais dois dedos encostados no nariz, de acordo com seu braço. O metro antigo é a medida de comprimento que vai da ponta do dedo indicador até a ponta do nariz do homem. O metro antigo é usado para medir canoa ubá. Para medir uma peça (tora de madeira), também é usado o metro antigo, conforme o comprimento que a pessoa precisa para fazer tábuas, flechais e pernamancas, exemplos, a medida é de três metros antigos em diante. Se o braço do homem for comprido não precisa medir com o dedo para fazer o metro antigo. Também usamos para medir as coisas, a braça, palmo, chave, dedo e polegada, braça marítima (tuez) e braça normal de um homem. Uma canoa pequena, um casco, uma montaria, uma canoa de dois bicos, uma canoa grande casco são medidos pela braça normal de um homem. (NUNES, 2013).

Monteiro e Nunes (2013) explicaram que na cultura Galibi-Marworno, no passado e hoje, são usadas medidas de comprimento que são adotadas na aldeia Kumaru- 
mã e nas suas proximidades. Estas medidas de comprimentos são (braça marítima, braça normal de um homem, metro antigo, braça, palmo, chave, dedo e polegada).

Nas medições das roças, canoa casco, canoa ubá, tabuas, flechais e pernamanca e outros objetos, os indígenas Galibi-Marworno fazem medições de coisas adotando um sistema de medida diferenciado em algumas práticas laborais, e que não são estudadas na disciplina de matemática nas escolas indígenas, mesmo sendo previsto o ensino de grandezas e medidas, voltando à realidade dos estudantes indígenas no Brasil. Estes conhecimentos matemáticos têm como objetivo medir e comparar medidas, utilizando instrumentos de medidas variados. (BRASIL, 1997; RUFFALDI, SPIRES, 2006).

Outros entrevistados falaram com relação as medidas de comprimento:

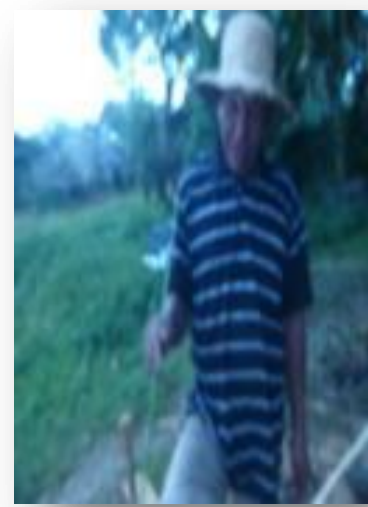

Fonte: Narciso, A. F. Fotografia da pesquisa, 2013b.

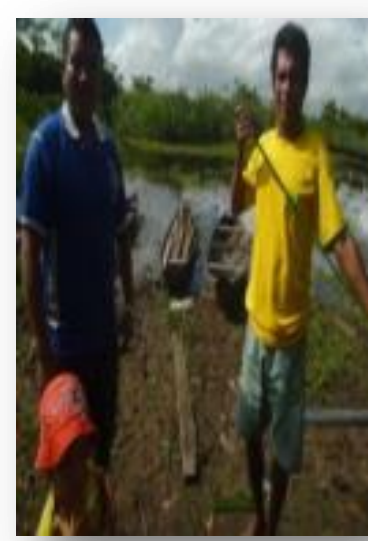

Os antigos mediam usando braça de um homem, é medido no mato uma canoa casco (kanũ kok). O metro antigo é medido numa vara na floresta, serve para medir peça (tora de madeira) para serrar tábuas e para enfalcar canoa ubá de sete a oito metros de comprimento em diante, e tábuas para cerca, parede de casa e assoalhar. Outro tipo de medida de comprimento para medir largura de uma tábua é palmo, chave e dedo. Para medir a espessura da tábua é o polegada e dedo. Para medir uma roça, usamos um homem em pé, com o braço erguido para cima, mais o terçado, que se chama braça marítima (tuéz). Essa medição é feita numa vara para cima, e depois escolhe o terreno na floresta e medi em braça quadrada, o comprimento da roça pode ser quarenta por trinta braça quadrada ou cinquenta por sessenta braça quadrada. (NARCISO, 2013).

Fonte: Narciso, A. F. Fotografia da pesquisa, $2013 b$.

Mauricio e Narciso (2013) confirmaram as informações que foram apresentadas nas entrevistas de Monteiro e Nunes (2013), com relação à maneira como os indígenas Galibi-Marworno mediam as coisas no passado recente, assim como na atualidade. Portanto, registrou-se novamente pelos entrevistados, que para fazer as medições de objetos durante algumas práticas laborais, os indígenas Galibi-Marworno são usam as unidades de medidas que são estudadas na Escola Indígena Estadual Camilo Narciso.

Os dois últimos entrevistados comentaram sobre medidas de comprimento, ins- 
trumento de medidas e unidades de medidas, o que se verifica abaixo:

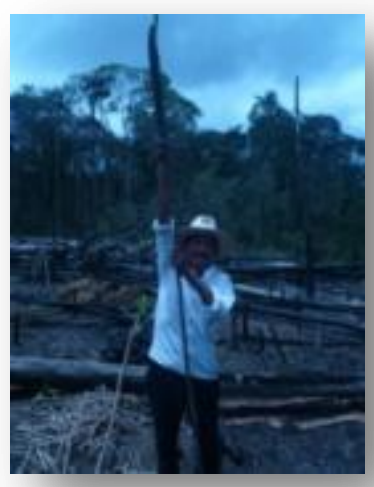

Fonte: Narciso, A. F. Fotografia da pesquisa, 2013b.

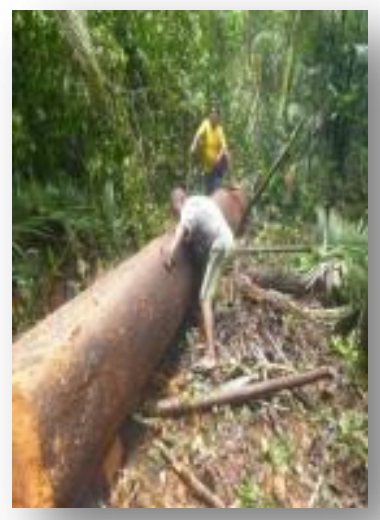

Fonte: Narciso, A. F. Fotografia da pesquisa, $2013 \mathrm{~b}$.
Antes nós não conhecíamos o metro do comércio, mas conhecia a braça normal de um homem para medir. Essa medida era usada em tempos antigos. Eu aprendi essa medida com meus ancestrais. A braça marítima (tuéz) era usada no passado para medir roça em braça marítima quadrada. A braça marítima é medida com um homem em pé que fica apoiado na ponta do dedo do pé, com braço erguido para cima mais o terçado erguido para cima. A braça normal de um homem serve para medir: canoa casco de pescar e para ir na roça, pernamanca, casa, canoa ubá e peça de madeira. Todos esses objetos são medidos por comprimentos e largura como: dois, dois e meio, três, três e meio, quatro, cinco, seis, sete, oito, nove, dez, onze até doze braças de um homem. Para lavrar uma peça de madeira de dois palmos de largura para serrar as tábuas largas que são medidas por um e meio polegada, duas polegadas ou dois dedos de espessura, depende do comprimento da tábua. Outro exemplo é a medida usada para lavrar uma madeira de um palmo de largura para serrar tábuas finas ou para cercas de casas. Isto depende do comprimento da tábua que é medida em um palmo de largura, com uma polegada ou um dedo de espessura. Como também a medida da falca que é de quatro braças, que tem dois dedos de espessura em relação às tábuas grossas, e, falca de três braça, um dedo de espessura em relação às tábuas finas. Para abrir uma canoa casco grande de quatro braças, é preciso que ela tenha um metro de largura que é medido em cinco palmos numa vara de cipó ou do mato que é igual a um metro antigo. A rodela de canoa casco é medida com compasso e a proa da canoa é marcada por cinco pontos, e, a popa é de três pontos com compasso. Os diferentes tipos de medidas para emberrumar as canoas, são: canoa de duas braças e meia de comprimento, com um dedo e meio de espessura; canoa de três braças de comprimento, com dois dedos de espessura; cano de quatro braças de comprimento, com dois dedos meio de espessura. Essas medidas vieram de tempos antigos e são usadas ainda hoje. (SANTOS, 2013).

Eu aprendi as medidas do passado com meu avô e pai. A canoa ubá é medida pelo metro antigo, como cinco, seis, sete e oito metros antigos em diante. A canoa casco é medida pela braça, e, depende do comprimento da canoa que a pessoa pretenda fazer, como exemplo: canoa de duas braças e meia de comprimento, canoa de quatro braças e meia de comprimento, canoa de quatro braças de comprimento, canoa de três braças e meia de comprimento, canoa de três braças de comprimento. Já a canoa casco mede três braças e dois palmos de comprimento. Ela é medida conforme o tamanho da madeira, se a peça da madeira for muito comprida, ela fica fina. Mas se a peça da madeira for curta, ela fica redonda. Para fazer o jamaxi que é usado para carregar a mandioca e outros produtos. O jamaxi mede cinco palmos de comprimento para adulto. Para criança, o jamaxi mede três palmos de comprimento. Esse é o metro antigo. Também tem a canoa de três braças de comprimento e canoa de quatro braças de comprimento. (CHARLES, 2013)

Estes entrevistados explicaram que são utilizadas medidas de comprimento, instrumento de medidas e unidades de medidas específicas em práticas laborais de agricul- 
tores e mestres Galibi-Marworno que são construtores de canoas, casas, peças de madeiras e jamaxis.

Os dados destas entrevistas nos permitiram compreender que mesmo estando em uso o sistema internacional de medidas nas sociedades, os indígenas GalibiMarworno empregam outro sistema de medida em algumas práticas laborais. Com relação aos instrumentos de medidas destas práticas laborais, elas são extraídas da natureza e em outras são partes do corpo humano.

Assim, como ocorre a transmissão desses modos de medir que são usados em algumas práticas laborais na cultura Galibi-Marworno?

A transmissão desses conhecimentos é ensinada para os jovens e seus filhos, como os nossos pais aprenderam dos avôs. Ela é transmitida no dia-a-dia para que nós não esqueçamos as medidas usadas em práticas na tradição GalibiMarworno. Um exemplo de medidas de comprimento é a braça marítima (tuéz), a braça normal de um homem e metro antigo que é medido numa varinha. Existem três formas de medir o metro antigo na tradição Galibi-Marworno: medindo cinco palmos numa vara do mato; um homem em pé com uma vara do mato até no umbigo; um homem de braço aberto para direita ou esquerda, segurando uma vara até a ponta do nariz, com a cabeça virada também para direita ou esquerda, mais 1 polegada que meça um metro do mato. O palmo, a chave, o dedo e o polegar sempre estão presentes na teoria (transmissão de conhecimentos) e nas práticas (atividades cotidianas) na Aldeia Kumarumã. (MONTEIRO, 2013).

Para contar ou explicar como as pessoas mediam antes na cultura GalibiMarworno para nós não esquecermos a nossa cultura. Um exemplo é o metro antigo. Essa medida de comprimento e outras são sempre usadas em toda a comunidade da Aldeia Kumarumã e nas proximidades da aldeia dentro da mata. Isto é feito porque na mata, muitas vezes nós não temos como usar a trena ou o metro padrão, por isso utilizamos as maneiras de medir dos nossos avôs. (NUNES, 2013).

A transmissão desses conhecimentos aos jovens tem que ser feita pelos indígenas mais velhos da Aldeia para aprender sobre as formas de medir. Se os jovens não acompanharem os mais velhos nunca irão aprender. Se não praticarmos no nosso cotidiano, iremos esquecer as maneiras de medir na cultura Galibi-Marworno. Um exemplo é o metro que é medido no mato, a braça marítima, a braça normal de um homem e outros. Na memória do nosso povo, existem as medidas de comprimento que são usadas e praticadas no cotidiano da comunidade. (MAURÍCIO, 2013).

Estes entrevistados explicaram que a transmissão dos modos de medir aos jovens ocorre naturalmente na educação indígena, pois são transmitidos de pais para fiIhos. Assim, é importante a participação dos indígenas mais velhos na transmissão desses conhecimentos.

Ainda a este respeito, outros entrevistados falaram que: 
Os conhecimentos sobre as maneiras de medir são transmitidos aos jovens pelos indígenas mais velhos. Eu aprendi com os mais velhos da Aldeia Kumarumã. As crianças aprendem na comunidade com o avô e o pai. (NARCISO, 2013).

A transmissão desses conhecimentos é repassada aos jovens. Eles aprendem na comunidade, trabalhando com os mais velhos. Os mais velhos transmitem esses conhecimentos para seus filhos, como medir canoa, roça, espessura de uma tabua e peça (tora de madeira). Essas maneiras de medir são praticadas nas proximidades da Aldeia Kumarumã e dentro da Aldeia. (SANTOS, 2013).

A transmissão desses conhecimentos é repassada aos jovens pelos avôs e pais. Eu aprendi com os mais velhos da comunidade. Eu ficava observando eles para aprender as maneiras de medir. Assim todo mundo mede da mesma maneira no seu trabalho, usando a braça normal de um homem, o metro medindo na vara (metro antigo), o palmo, o dedo, a chave, a braça marítima e outros. (CHARLES, 2013).

Estes entrevistados explicam que as maneiras de medir que estão em uso na aldeia Kumarumã e suas proximidades, são aprendidas pelos jovens através dos mais veIhos, pois são eles que conhecem as maneiras de medir que são praticadas pelos indígenas Galibi-Marworno em atividades laborais. Por último, os entrevistados respondem a pergunta: Nas práticas cotidianas que ocorrem na Aldeia Kumarumã é usada alguma maneira de medir que é diferente do que se aprende na escola indígena?

Sim. É uma matemática indígena. Todas essas coisas como palmo, metro antigo, braça marítima, chave, braça normal de um homem, dedo e outros é uma matemática indígena que dá certo em qualquer atividade. Exemplo para fazer uma canoa ubá de oito metros antigo de comprimento, a falca tem que ser de nove metros antigo de comprimento. É preciso pensar antes o trabalho a ser realizada para poder dá certo a medida. (MONTEIRO, 2013).

Sim. É uma matemática indígena e um estudo muito importante. Quando eu era jovem, não sabia o que o meu pai estava fazendo em suas atividades, como medir uma canoa, medir uma peça de madeira, medir uma falca e outros. Tudo que eu vi, é uma matemática indígena, que eu aprendi com meu pai. (NUNES, 2013).

Sim, porque as medidas braça marítima, braça normal de um homem, metro antigo e outras, é a matemática indígena. (MAURICIO, 2013).

Eles explicaram que, em algumas práticas cotidianas na Aldeia Kumarumã, são usadas pelos indígenas Galibi-Marworno uma maneira de medir que é diferente do que se aprende no ensino de matemática na escola indígena.

Já outros entrevistados responderam que: 
É importante para escola indígena as medidas que usamos. Se deixarmos de medir da nossa maneira, os nossos filhos e netos irão esquecer esses conhecimentos. É preciso ensinar as nossas medidas para eles, para preservar a nossa cultura e que na escola indígena transmita esse conhecimento de geração para geração. Eu faço esse trabalho quase todo dia e tudo isso é a matemática indígena. (NARCISO, 2013).

As maneiras de medir é uma matemática que veio dos tempos de nossos avôs. Exemplo, para bater uma linha, se nivela uma peça para tábua sair direita. A peça de madeira que vai ser serrada é medida em dedo, polegada e chave. Para abrir uma canoa é preciso medir cinco palmos de comprimento numa vara e para medir uma canoa de quatro braças de comprimento e um metro antigo de largura são usadas essas medidas para abrir a canoa. A escola indígena tem que valorizar as nossas maneiras de medir. (SANTOS, 2013).

É a matemática indígena (matematxik ẽdjiẽ) que eu aprendi com meu pai e avô. Um exemplo é o metro antigo que nós medimos numa vara do mato, passando a ponta do nariz, com a cabeça erguida para direita ou esquerda mais dos dedos, e, passando o nariz. (CHARLES, 2013).

A partir da realização das entrevistas desta pesquisa, concluímos que na atualidade, são utilizados sete tipos de medidas em algumas práticas laborais pelos indígenas Galibi-Marworno, o que sistematizamos na Tabela 2 deste artigo:

\begin{tabular}{|c|c|c|c|}
\hline Tipos de medidas & $\begin{array}{l}\text { Unidade de } \\
\text { medida }\end{array}$ & $\begin{array}{l}\text { Instrumento de me- } \\
\text { dida }\end{array}$ & Exemplo de medições \\
\hline Braça marítima & $\begin{array}{l}\text { Braça marítima } \\
\text { quadrada ou } \\
\text { braça quadrada }\end{array}$ & $\begin{array}{l}\text { O corpo humano, a } \\
\text { vara do mato e o } \\
\text { terçado. }\end{array}$ & $\begin{array}{l}\text { Área de terreno de uma roça: } 60 \text { por } 40 \\
\text { braça marítima quadrada. }\end{array}$ \\
\hline $\begin{array}{l}\text { Braça normal de } \\
\text { um homem }\end{array}$ & Braça & $\begin{array}{l}\text { O corpo humano e } \\
\text { os braços abertos na } \\
\text { horizontal. }\end{array}$ & $\begin{array}{l}\text { Comprimento de canoas: três braças ou } \\
\text { duas braças e meia em diante. Sendo o } \\
\text { comprimento máximo de quatro braças e } \\
\text { meia. }\end{array}$ \\
\hline Chave & Chave & $\begin{array}{l}\text { O dedo polegar e o } \\
\text { dedo indicador. }\end{array}$ & $\begin{array}{l}\text { Largura ou comprimento de canoas, tá- } \\
\text { buas (ripas, flechais e pernamancas): } \\
\text { canoa de três braças e uma chave; flechal } \\
\text { de quatro metro antigo e duas chaves. }\end{array}$ \\
\hline Dedo & Dedo & $\begin{array}{l}\text { Um dedo, dois ou } \\
\text { mais dedos juntos. }\end{array}$ & $\begin{array}{l}\text { Espessura de tábuas e canoas: tábua de } \\
\text { oito metros antigo e dois dedos de espes- } \\
\text { sura; canoa de duas braças e meia, e, um } \\
\text { dedo e meio de espessura da beira da } \\
\text { canoa (Canoa casco pequena). }\end{array}$ \\
\hline Metro antigo & $\begin{array}{l}\text { Metro antigo } \\
\text { ou metro do } \\
\text { mato }\end{array}$ & $\begin{array}{l}\text { O corpo humano e a } \\
\text { vara do mato. }\end{array}$ & $\begin{array}{l}\text { Comprimento de peças de madeira e } \\
\text { outros objetos: dez metros antigo; quatro } \\
\text { metro antigo e dois palmos. }\end{array}$ \\
\hline
\end{tabular}




\begin{tabular}{c|c|c|l}
\hline \multirow{3}{*}{ Palmo } & Palmo & $\begin{array}{c}\text { Comprimento e largura de tábuas e ca- } \\
\text { A mão espalmada } \\
\text { que vai do dedo } \\
\text { polegar ao dedo } \\
\text { mínimo. }\end{array}$ & $\begin{array}{l}\text { noas: Tábua de nove metros antigo de } \\
\text { comprimento e dois palmos de largura; } \\
\text { canoa de sete metros antigo e três pal- } \\
\text { mos de comprimento (canoa ubá); jamaxi } \\
\text { de adulto de cinco palmos de compri- } \\
\text { mento e jamaxi de criança de três palmo } \\
\text { de comprimento. }\end{array}$ \\
\hline Polegada & Polegada & $\begin{array}{c}\text { O osso falangeta do } \\
\text { dedo polegar. }\end{array}$ & $\begin{array}{l}\text { Grossura de tábuas: Tábua de três metros } \\
\text { antigo e uma polegada de grossura. }\end{array}$ \\
\hline
\end{tabular}

Tabela 2 - Sistema de medida diferenciado em uso em algumas práticas laborais.

Fonte: Elaborado pelos autores a partir da análise do objeto de estudo.

No Brasil, o "Sistema Internacional de Unidades - $\mathrm{SI}^{8}$ é ensinado à população urbana e rural nas escolas públicas, o que inclui a população indígena. Mesmo assim, os indígenas Galibi-Marworno não usam as unidades de medidas deste sistema, em atividades da agricultura e construções de canoas, casas, peças de madeiras e jamaxis, o que se observa na (Tabela 2).

Com base na análise das entrevistas constatou-se que não existe convenção matemática entre as unidades de medidas do sistema de medida diferenciado para o grupo pesquisado, o que se justifica porque cada coisa ou objeto pode assumir diversos tamanhos no processo de medição. As medições dependem do tipo de recurso natural e da parte do corpo humano que é usado no ato de medir.

Para entender o sistema de medida diferenciado que é usado na Aldeia Kumarumã e suas proximidades, é preciso conhecer de que forma os indígenas GalibiMarworno convivem com a natureza.

A natureza é importante para os Povos Indígenas do Norte do Amapá e do Pará, pois cada grupo étnico tem à sua maneira de respeitar e conviver com a natureza. Ela oferece os espaços, as condições e os recursos naturais para que se desenvolvam as práticas cotidianas, como também os seus cálculos matemáticos mentais.

Através do contato com a natureza, os indígenas Galibi-Marworno utilizam os recursos naturais para sua subsistência e sobrevivência. Os recursos extraídos da natureza são usados em atividades do modo de vida indígena. Nem sempre a matemática indígena aparece em todas as práticas cotidianas, mas ela é presente na memória dos Povos Indígenas e em algumas práticas laborais, como: na confecção das marcas, na medição do tempo em práticas de pesca ou caça, na preparação de remédios tradicionais, na construção de canoas ou jamaxis e na preparação da roça com uso de um sistema de medida diferenciado.

É importante dizer que este sistema de medida diferenciado se caracteriza por envolver medidas de comprimento, de largura, de espessura e de área de terrenos, o que na visão dos entrevistados da pesquisa é entendido como parte da matemática indígena e como prática laboral presente na cultura Galibi-Marworno.

${ }^{8}$ Para saber a este respeito, vide: ROZEMBERG, J. M. O Sistema Internacional de Unidades - SI, 2006. 
Mas se comparado as suas unidades de medidas, como o sistema internacional de unidades, os dados coletados na pesquisa qualitativa levam-nos a perceber, em síntese, que se referem à medida de comprimento e medida de superfície, o que decorre do roteiro de entrevista temática que delimitou o objeto de estudo.

Assim, as medidas de largura e espessura também podem ser interpretadas como parte das medidas de comprimento dos objetos que foram exemplificados pelos indígenas Galibi-Marworno. O fato do resultado da pesquisa não descrever outras unidades de medidas, não implica que estas não existam ou que não são utilizadas nos processos de medição, uma vez que, os próprios indígenas Galibi-Marworno, que foram entrevistados desta pesquisa, comentaram que existem outras unidades de medidas.

Desse modo, o tema deste trabalho é importante por sistematizar uma parte do sistema de medida diferenciado adotado em algumas práticas laborais, que tratam de atividades específicas desenvolvidas pelos indígenas Galibi-Marworno, conforme descritas na (Tabela 2) e documentadas nas entrevistas textualizadas.

\section{CONSIDERAÇÕES FINAIS}

O resultado deste estudo é uma discussão de pesquisa em etnomatemática. Com relação à palavra etnomatemática (etnomatematxik) é preciso lembrar que:

Diferentemente do que sugere o nome, etnomatemática não é o estudo apenas de "matemáticas das diversas etnias". Mais do que isso, é o estudo das várias maneiras, técnicas, habilidades (technés ou ticas) de explicar, entender, lidar e conviver (matema) nos distintos contextos naturais e socioeconômicos, espacial e temporalmente diferenciados da realidade (etno). (D’AMBROSIO, 2001, p. 125).

Portanto, estudamos algumas maneiras de medir que se manifestam em práticas laborais dos indígenas Galibi-Marworno (ticas). As casas dos três entrevistados localizadas na Aldeia Kumarumã, o local de trabalho de um agricultor Galibi-Marworno é chamado de Sítio Casa Velha e as proximidades do local de trabalho de um mestre construtor de canoas e de um agricultor situadas perto Igarapé Paramuaka, são os contextos naturais e espaciais em que ocorreram as entrevistas (etno). O modo de entender e explicar do grupo de entrevistado (matema) é o que caracteriza este estudo uma pesquisa em etnomatemática; em língua Kheuol, pexkiz dji etnomatematxik.

Com base nos dados coletados na pesquisa qualitativa, concluímos que os indígenas Galibi-Marworno usam em algumas práticas cotidianas um sistema de medida diferenciado que envolve, em resumo:

1)Medida de comprimento ou mizuhe dji lõdjio: braça normal de um homem, metro antigo, dedo, chave e palmo;

2) Medida de largura ou mizuhe dji lajo: metro antigo, dedo, chave e palmo;

3) Medida de grossura ou mizuhe dji ghoso: polegada e dedo;

4) Medida de terreno ou mizuhe dji tehẽ: braça marítima ou braça marítima 
quadrada.

Este sistema de medida diferenciado é presente no convívio com a natureza e matem-se vivo na memória dos indígenas mais velhos, pois são eles que transmitem oralmente, o que recordam e sabem sobre os modos de medir que eram usados pelos seus avôs para seus filhos e netos em outras épocas.

Esta pesquisa em etnomatemática provoca reflexões sobre o que é ensinado e praticado em relação ao saber matemático no contexto da educação escolar indígena, bem como instiga-nos a aprofundar o tema no futuro através de outra pesquisa, pois não estudamos as origens do sistema de medida diferenciado ou suas relações com outros sistemas de medidas e pesos adotados por outros povos em séculos passados.

\section{REFERÊNCIAS}

BRASIL. Secretaria de Educação Fundamental. Parâmetros Curriculares Nacionais: Introdução aos parâmetros curriculares nacionais. Brasília: MEC/SEF, 1997. v. 3.

BRASIL. Parâmetros Curriculares Nacionais Ensino Médio: Ciências da Natureza, Matemática e suas Tecnologias. Brasília: MEC/SEB, 2000. v. 3.

CARDOSO, W. T. O Céu dos Tukanos na Escola Yupuri: Construindo um calendário astronômico. (Tese de Doutorado em Educação Matemática). Pontifícia Universidade Católica de São Paulo. São Paulo, 2007. Disponível em: https://sapientia.pucsp.br/ handle/handle/11272, Acesso: 20/05/2017.

CHARLES, A. C. N. Entrevista cedida à Alarcidio Figueiredo Narciso. Oiapoque: Aldeia Kumarumã, 2013.

COSTA, E. S. Os tecidos de Gana como atividade escolar: uma intervenção etnomatemática para a sala de aula. (Dissertação de Mestrado em Educação Matemática). Pontifícia Universidade Católica de São Paulo. São Paulo, 2008. Disponível em: https://sapientia.pucsp.br/handle/handle/11295, Acesso: 20/05/2017.

D’AMBRosio, U. Etnomatemática. Arte ou Técnica de Explicar e Conhecer. 5ª ed. São Paulo: Ática, 1998.

Etnomatemática: Elo entre as tradições e a modernidade. $2^{\underline{a}}$ ed. $1^{\circ}$ reimp. Belo Horizonte: Autêntica, 2005. (Col. Tendências em Educação Matemática, v. 1).

LONDOÑO, L. K. B. "La medida” e nun contexto de escuela indígena: el caso del Pueblo Tule y el caso del Pueblo Embera-Chamí. (Trabajo de Grado de Licenciatura en Educación Básica com Énfasis en Matemáticas). Universidad de Antioquia. Medellín, 2009. Disponível em: http://etnomatematica.org/trabgrado/medida Berrio.pdf, Acesso: 20/05/2017.

MAURíCIO, L. Entrevista cedida a Alarcidio Figueiredo Narciso. Oiapoque: Aldeia Kumarumã, 2013. 
MELO, E. A. P. Investigação etnomatemática em contextos indígenas: caminhos para a reorientação da prática pedagógica. (Dissertação de Mestrado em Educação). Universidade Federal do Rio Grande do Norte. Natal. 2007. Disponível em: https://reposi torio.ufrn.br/jspui/bitstream/123456789/14193/1/ElisangelaAPM.pdf, Acesso: 20/05/2017.

MONTEIRO, H. Entrevista cedida a Alarcidio Figueiredo Narciso. Oiapoque: Aldeia Kumarumã, 2013.

NARCISO, A. F. Sistema de Medidas em Práticas Laborais na Cultura Galibi-Marworno: Uma pesquisa em etnomatemática. (Monografia da Licenciatura Intercultural Indígena). Universidade Federal do Amapá. Oiapoque, 2014. Disponível em: http://www2 .unifap.br/nuphce/files/2015/08/TCC-Alarcidio-Figueiredo-Narciso1.pdf, Acesso: 20/ 05/2017.

NARCISO, A. S. Entrevista cedida a Alarcidio Figueiredo Narciso. Oiapoque: Aldeia Kumarumã, 2013.

NUNES, O. S. Entrevista cedida a Alarcidio Figueiredo Narciso. Oiapoque: Aldeia Kumarumã, 2013.

ROSA, M.; OREY, D. C. Las Raíces Históricas del Programa Etnomatemáticas. Revista Latinoamericana de Investigación en Matemática Educativa, v. 8, n. 3, 2005, p. 363377. Disponível em: http://www.redalyc.org/pdf/335/33508307.pdf, Acesso: 20/05/ 2017.

ROZEMBERG, J. M. O Sistema Internacional de Unidades - SI. $3^{\text {a }}$ ed. rev. e ampl. São Paulo: Instituto Mauá de Tecnologia, 2006. Disponível em: http://maua.br/files/arquivos/ o-sistema-internacional-de-unidades-si-3.a-edicao.pdf, Acesso: 20/05/2017.

RUFFALDI, N; SPIRES, R. (Coord.) Currículo de Ensino Fundamental nas Escolas Indígenas: Karipuna, Galibi-Marworno, Palikur e Galibi-Kalinã no município de Oiapoque. $2^{\text {a }}$ ed. Belém: CIMI/MENSAGEIRO, 2006.

SANTOS, N. Marcas Indígenas do Povo Galibi-Marworno: O despertar do ensino da matemática na escola indígena. (Monografia de Licenciatura em Educação Escolar Indígena). Universidade Federal do Amapá. Macapá, 2011. Disponível em: http://www2. unifap.br/nuphce/files/2015/08/TCC-Naldo-dos-Santos.pdf, Acesso: 20/05/2017.

SANTO, S. F. Entrevista cedida a Alarcidio Figueiredo Narciso. Oiapoque: Aldeia Kumarumã, 2013.

UNIVERSIDADE FEDERAL DO AMAPÁ. Projeto Político Pedagógico do Curso Educação Escolar Indígena. Macapá, 2005.

UNIVERSIDADE FEDERAL DO AMAPÁ. Edital nº 008/2015/DEX/PROEAC/UNIFAP. Macapá, 2015. Disponível em: http://www.unifap.br/public/index/view/categoria/6/tag postagem/4/page/1/id/6275, Acesso: 20/05/2017. 
UNIVESIDADE FEDERAL DO AMAPÁ. Linhas de atuação do Núcleo de Pesquisa História da Ciência e Ensino. Disponíveis em: http://www2.unifap.br/nuphce/pagina-exem plo/linhas-de-atuacao/, Acesso: 20/05/2017.

VASQUEZ, E. L. Sociedade Cativa. Entre cultura escolar e cultura prisional: uma incursão pela ciência penitenciária. (Dissertação de Mestrado em História da Ciência). Pontifícia Universidade de São Paulo. São Paulo, 2008. Disponível em: https://sapientia. pucsp.br/handle/handle/13381, Acesso: 20/05/2017.

(c) (†)

License information: This is an open-access article distributed under the terms of the Creative Commons Attribution License, which permits unrestricted use, distribution, and reproduction in any medium, provided the original work is properly cited.

Article received on May 25, 2017.

Accepted on January 20, 2018. 